\title{
Virtual reality relaxation for the general population: a systematic review
}

\author{
Simon Riches ${ }^{1,2,3} \cdot$ Lisa Azevedo ${ }^{3,4} \cdot$ Leanne Bird $^{5} \cdot$ Sara Pisani $^{4} \cdot$ Lucia Valmaggia $^{1,3}$
}

Received: 7 December 2020 / Accepted: 18 May 2021 / Published online: 13 June 2021

(c) The Author(s) 2021

\begin{abstract}
Purpose Relaxation has significant restorative properties and implications for public health. However, modern, busy lives leave limiting time for relaxation. Virtual reality (VR) experiences of pleasant and calming virtual environments, accessed with a head-mounted display (HMD), appear to promote relaxation. This study aimed to provide a systematic review of feasibility, acceptability, and effectiveness of studies that use VR to promote relaxation in the general population (PROSPERO 195,804).

Methods Web of Science, PsycINFO, Embase, and MEDLINE were searched until 29th June 2020. Studies were included in the review if they used HMD technology to present virtual environments that aimed to promote or measure relaxation, or relaxation-related variables. The Effective Public Health Practice Project (EPHPP) quality assessment tool was used to assess methodological quality of studies.

Results 6403 articles were identified through database searching. Nineteen studies published between 2007 and 2020, with 1278 participants, were included in the review. Of these, thirteen were controlled studies. Studies predominantly used natural audio-visual stimuli to promote relaxation. Findings indicate feasibility, acceptability, and short-term effectiveness of VR to increase relaxation and reduce stress. Six studies received an EPHPP rating of 'strong', seven were 'moderate', and six were 'weak'.

Conclusions VR may be a useful tool to promote relaxation in the general population, especially during the COVID-19 pandemic, when stress is increasing worldwide. However, methodological limitations, such as limited randomised controlled trials and longer-term evidence, mean that these conclusions should be drawn with caution. More robust studies are needed to support this promising area of VR relaxation.
\end{abstract}

Keywords Virtual environment $\cdot$ Relaxation technique $\cdot$ Stress management $\cdot$ Restoration $\cdot$ Wellbeing $\cdot$ COVID-19

Simon Riches

simon.j.riches@kcl.ac.uk

1 Department of Psychology, Institute of Psychiatry, Psychology \& Neuroscience, King's College London, De Crespigny Park, London SE5 8AF, UK

2 Social, Genetic and Developmental Psychiatry Centre, Institute of Psychiatry, Psychology \& Neuroscience, King's College London, London SE5 8AF, UK

3 South London and Maudsley NHS Foundation Trust, Bethlem Royal Hospital, Monks Orchard Road, Beckenham BR3 3BX, Kent, UK

4 Department of Psychosis Studies, Institute of Psychiatry, Psychology \& Neuroscience, King's College London, London SE5 8AF, UK

5 Division of Psychology and Mental Health, Faculty of Biology, Medicine and Health, School of Health Sciences, University of Manchester, Manchester M13 9PL, UK

\section{Introduction}

Relaxation is a state of calmness that helps to release the body and mind from tension [1]. Systematic reviews indicate that relaxation techniques are cost-effective, safe, and practical; they can be easily taught and used as stress management to enhance general wellbeing and mental health [2]. Techniques and practices, such as progressive muscle relaxation, guided imagery, deep breathing, yoga and meditation can be utilised to foster a state of relaxation and positive wellbeing [2], and target a broad spectrum of health and functioning, with evidence for improvements in cognition, respiration, cardiovascular disease, body mass index, blood pressure, diabetes, and joint disorders [3]. With these techniques and practices, elevated heart rate and blood pressure can return to normal levels and psychophysiological arousal can be 
counteracted with more positive emotions, potentially reducing psychopathological symptoms, psychological distress, and improving subjective wellbeing [1].

Modern life can hinder relaxation practices, with busy schedules and time constraints limiting opportunities and optimal environments for relaxation; while limited time for working aged adults to relax has been shown to exacerbate stress, with evidence of a relationship between elevated stress and an inability to relax [4]. On average, problems related to stress affect one in six working adults [5]. Prolonged exposure to stressors or chronic stress is linked to physical health conditions, such as cardiovascular disease, diabetes, cancer, and autoimmune syndromes [6], as well as psychological distress, depression, anxiety, and substance abuse [7]. Furthermore, COVID-19 is exacerbating stress across the world [8]. Given these obstacles to relaxation, and the huge need to mitigate the psychological impact of stress during the pandemic [9], innovative interventions are needed.

Virtual reality (VR) is at the forefront of technological advancements in mental health care [10]. 'VR' typically refers to immersive and interactive head-mounted display (HMD) technology [11], which offers accessible ways to enable relaxation through visualisation, engagement, and immersion with pleasant virtual environments [12, 13]. Experiencing calm virtual audio-visual environments removes users from stressful situations, aiding stress management and relaxation amidst the challenges of everyday life. Increases in relaxation, as well as decreases in stress, arousal and anxiety, have been shown to result from exposure to pleasant virtual environments [13, 14].

Previous systematic reviews have focussed on traditional relaxation techniques targeted at people with health conditions $[1,2,15]$. Despite existing evidence supporting the restorative effects of experiencing pleasant virtual environments, systematic reviews to date have not synthesised studies of HMDs that use virtual environments to support or promote relaxation in healthy participants from the general population [16]. This systematic review aims to synthesise the evidence on the feasibility, acceptability, and effectiveness of HMD relaxation in promoting relaxation in the general population (PROSPERO 195,804).

\section{Methods}

\section{Search strategy}

This review was carried out in accordance with Preferred Reporting Items for Systematic Reviews and Meta-Analyses (PRISMA) [17]. Findings were synthesised using a narrative approach. Web of Science, PsycINFO, Embase, and MEDLINE were searched until 29th June 2020. Search terms were: "virtual real*" OR "virtual-real*" OR "VR" OR "virtual enviro*" OR "virtual character*" OR "VCs" OR "avatar*" AND "relax*" OR "autogen*" OR "meditat*" OR "mindful*" OR "rest*" OR "PMR" OR "progressive muscle" OR "imagery" OR "breath*" OR "distract*" OR "wellness" OR "wellbeing" OR "well-being”. Databases were searched for keyword, title, and abstract information. When searching PsycINFO on the Ovid platform, the 'explode' function was used to search key subject headings. Database searches were limited by journal articles and English language. Data were extracted and screened with reference management software Endnote. Dissertations, conference proceedings, and abstracts were excluded. Reference lists of key papers were screened. Two reviewers (LA, SP) independently conducted all searching and screening in consultation with other researchers (SR, LB).

\section{Inclusion and exclusion criteria}

Studies were included in the review if they (a) were published in a peer-reviewed journal; (b) were written in English; (c) included an experimental study design; (d) presented original data; (e) tested members of the general population; (f) $N \geq 5$; (g) included virtual environments that aimed to promote or measure relaxation or relaxation-related variables; and (h) presented immersive and interactive, three-dimensional virtual environments in HMD. Papers were excluded if they (a) tested a clinical population; (b) targeted specific anxieties or anxiety disorders; or (c) presented virtual environments in two-dimensional graphics on screens or caves.

\section{Quality assessment}

Quality ratings of included studies were carried out by two independent reviewers (LA, SP) using the Effective Public Health Practice Project (EPHPP) quality assessment tool for quantitative studies [18]. Quality rating were calculated in consultation with other researchers (SR, LB). EPHPP rates six methodological domains: selection bias, study design, confounders, blinding, data collection, and withdrawals. A global rating for each study is calculated as: 'strong' = no weak subscale ratings; 'moderate' $=$ one weak subscale rating; 'weak' = two or more weak subscale ratings.

\section{Results}

\section{Study characteristics}

A total of 6403 articles were identified through database searching and four articles through other sources. The full texts of 44 studies were screened and, of these, nineteen met 
inclusion criteria and were included in the review. See Fig. 1 for the Preferred Reporting Items for Systematic Reviews and Meta-Analyses (PRISMA) flow diagram. See Table 1 for study characteristics. The nineteen included studies were published between 2007 and 2020. There were thirteen controlled studies, of which four were randomised controlled trials (RCTs). Studies were conducted in USA $(N=3)$, Germany $(N=3)$, Australia $(N=3)$, Italy $(N=3)$, China $(N=3)$, Spain $(N=2)$, Belgium $(N=1)$, and Canada $(N=1)$. A total of 1,278 participants took part in the studies, of which 662 participants experienced an HMD intervention. The number of participants recruited across studies ranged from sixteen to 190 . Two studies had sample sizes over $100[19,20]$. Eleven studies used student participants. Most participants across studies were in the 20-40 age range. Eighteen studies contained one intervention session and one contained four intervention sessions, with the duration of each session ranging from three minutes to one hour. Follow-up sessions were reported in two studies and took place two weeks [21] or one month and three months [22] following the initial intervention. HMDs used in studies were Oculus Rift $(N=8)$, Oculus Go $(N=2)$, Samsung Gear $(N=2)$, Sony Glassroom $(N=2)$, Pico Goblin $(N=1)$, nVIS $(N=1)$, and HTC Vive $(N=1)$. Two studies included no information on HMD branding. Of these, one reported the inclusion of second-generation VR glasses of the illusion mirror type [23] and another outlined $800 \times 600$ resolution VR HMD with head tracking [24].

Ten studies included virtual environments consisting only of nature-related stimuli, such as trees, foliage, water, animals, clouds, lakes, rivers, beaches, forests, rocks, and
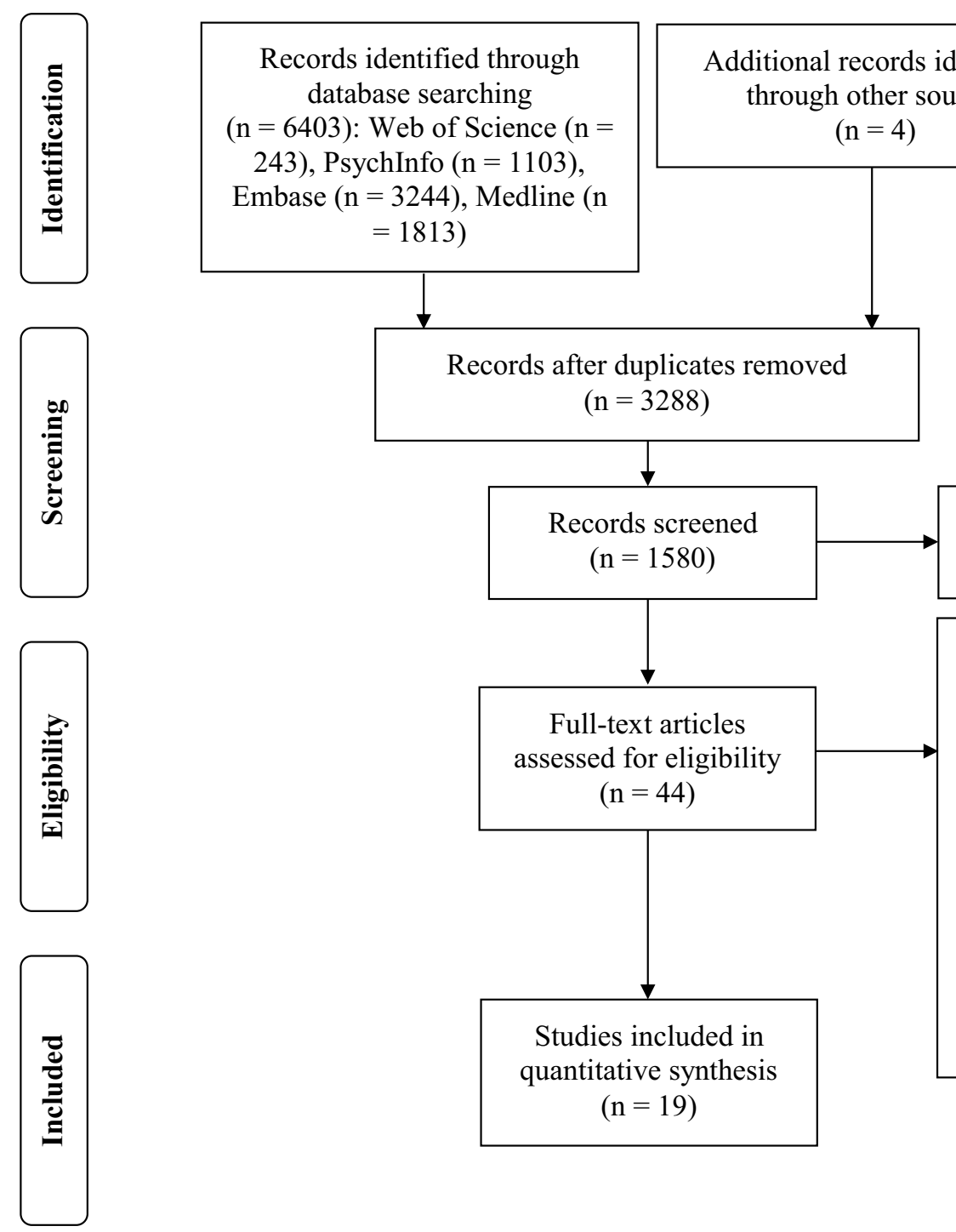

\section{Records excluded} $(\mathrm{n}=1708)$

Full-text articles excluded, with reasons $(\mathrm{n}=25)$ : not HMD $(\mathrm{n}=$ 8), not relaxation ( $\mathrm{n}=$ 7), non-empirical ( $\mathrm{n}=$ 4), not a journal article $(\mathrm{n}=2)$, not in English (n $=1$ ), tested members of a clinical population $(\mathrm{n}=1)$, targeted specific anxieties $(\mathrm{n}=1)$, duplicate data $(\mathrm{n}=1)$

Fig. 1 Preferred Reporting Items for Systematic Reviews and Meta-Analyses (PRISMA) flow diagram of studies on virtual reality relaxation for the general population 


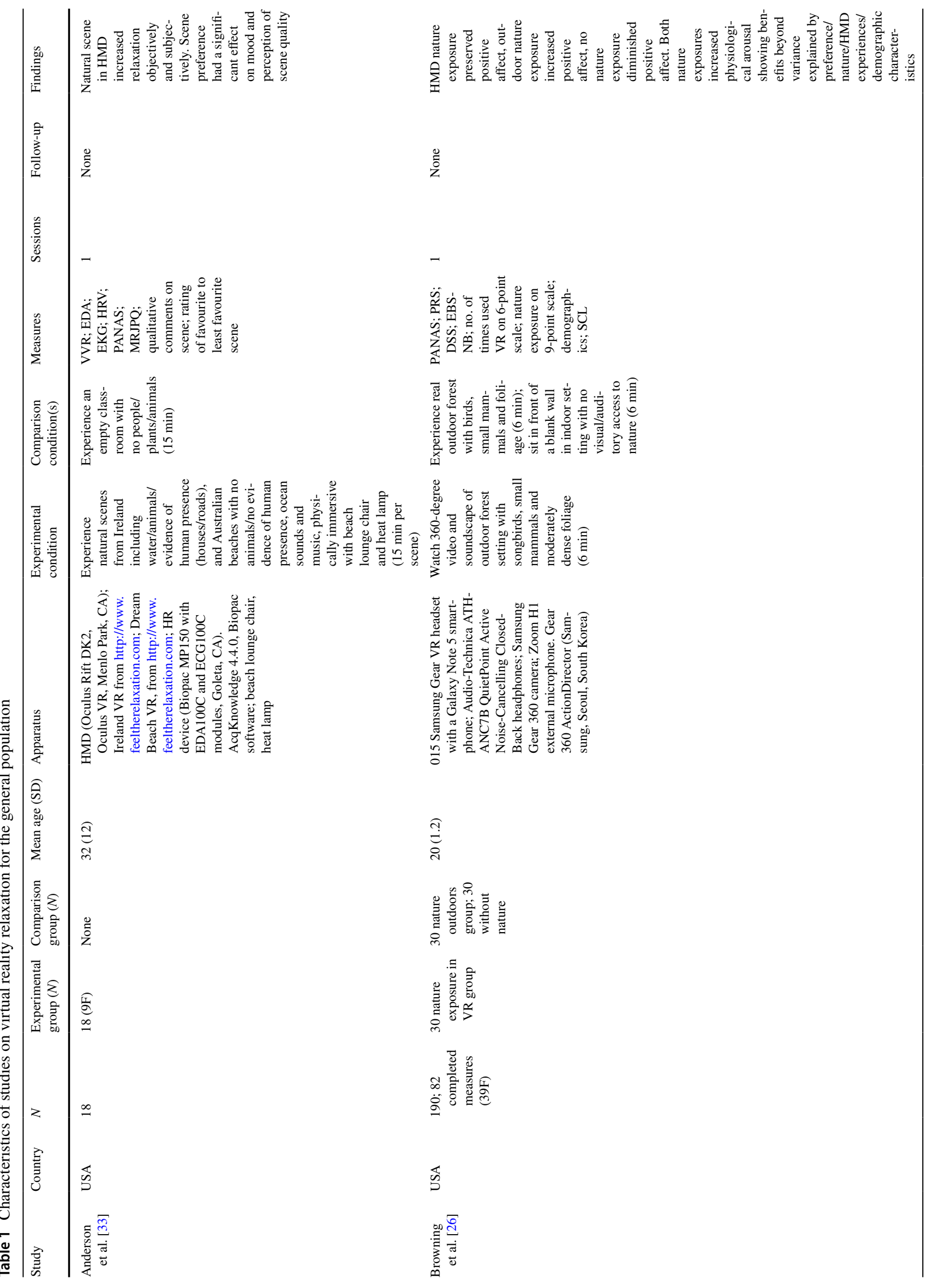




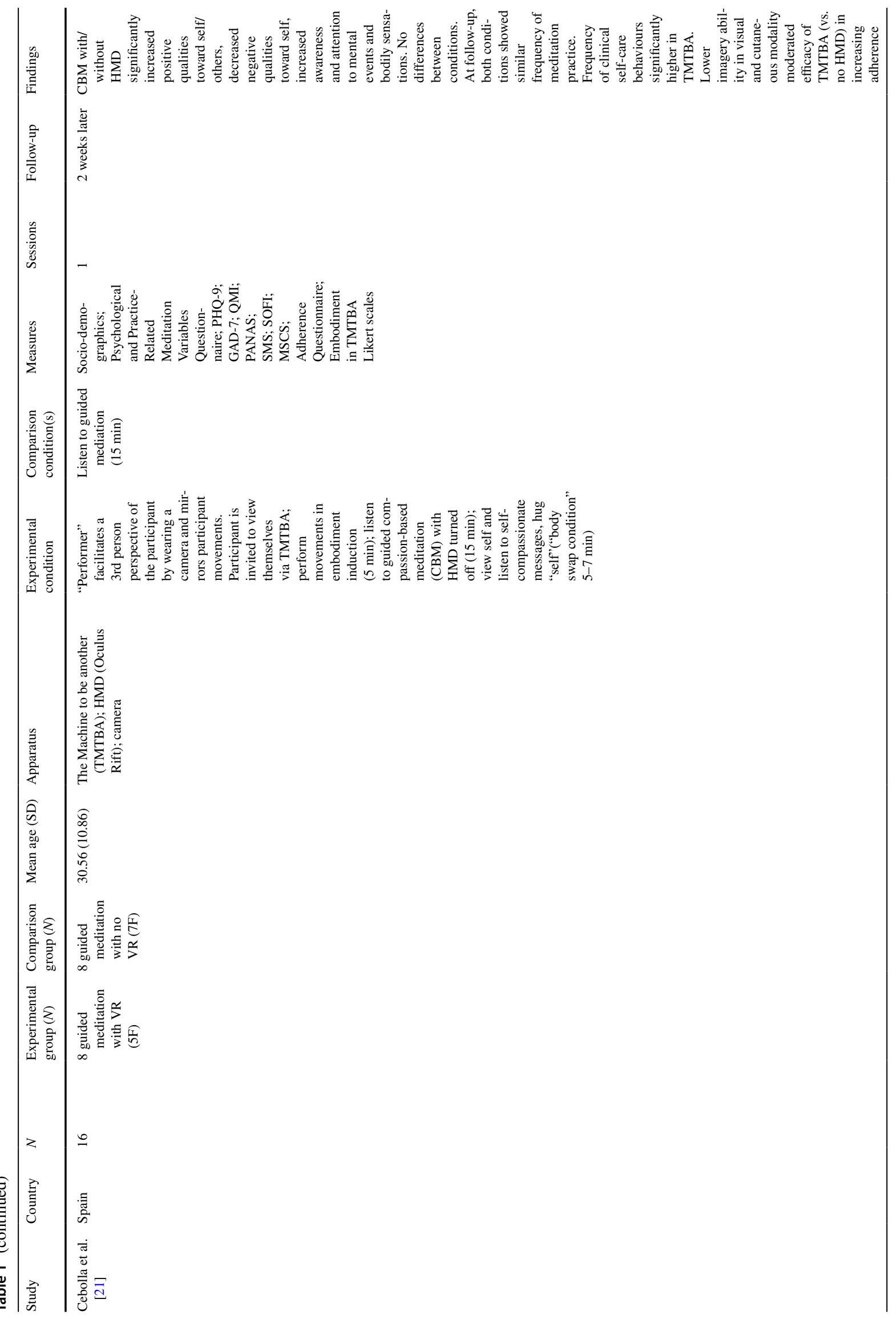




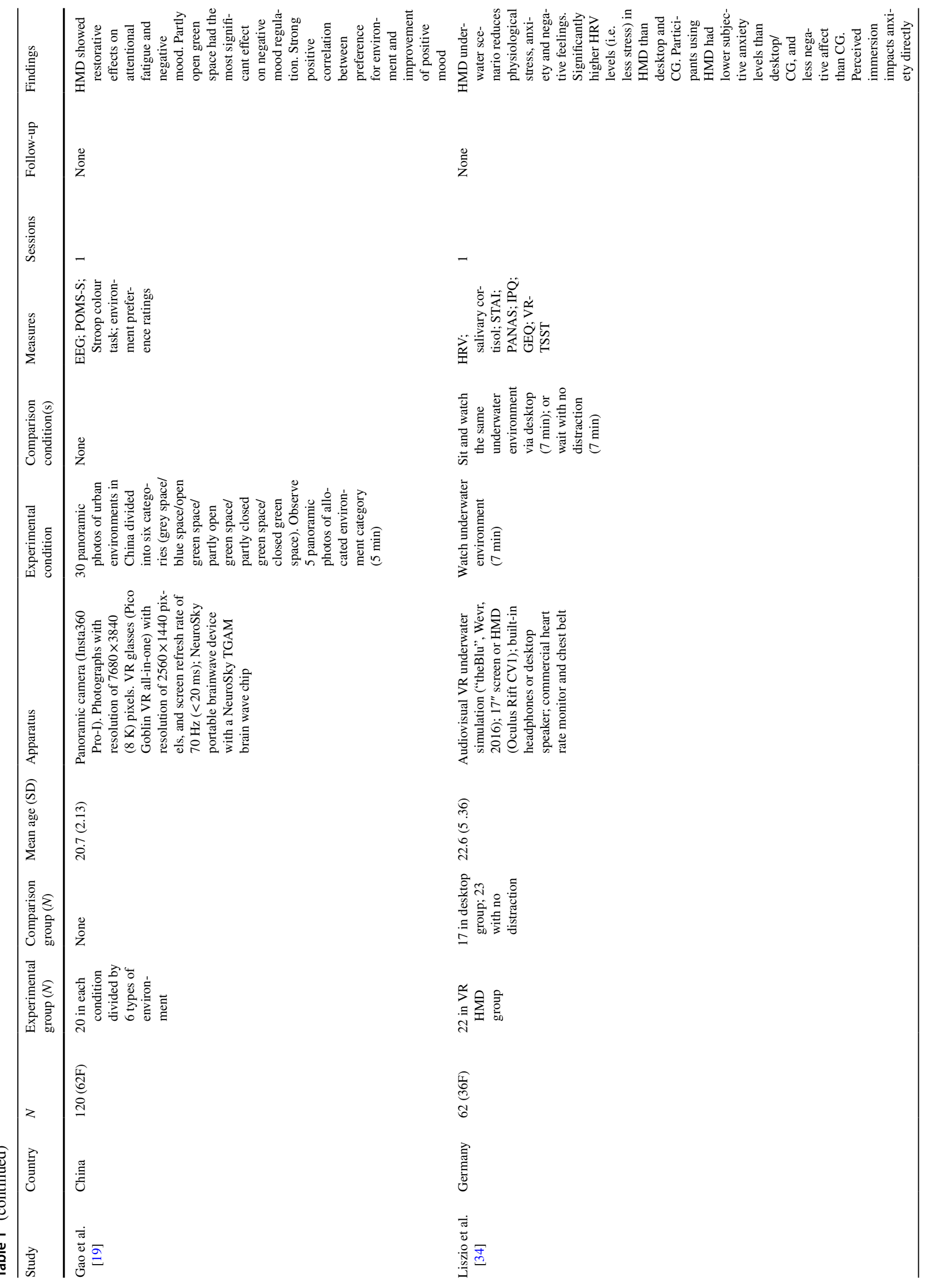




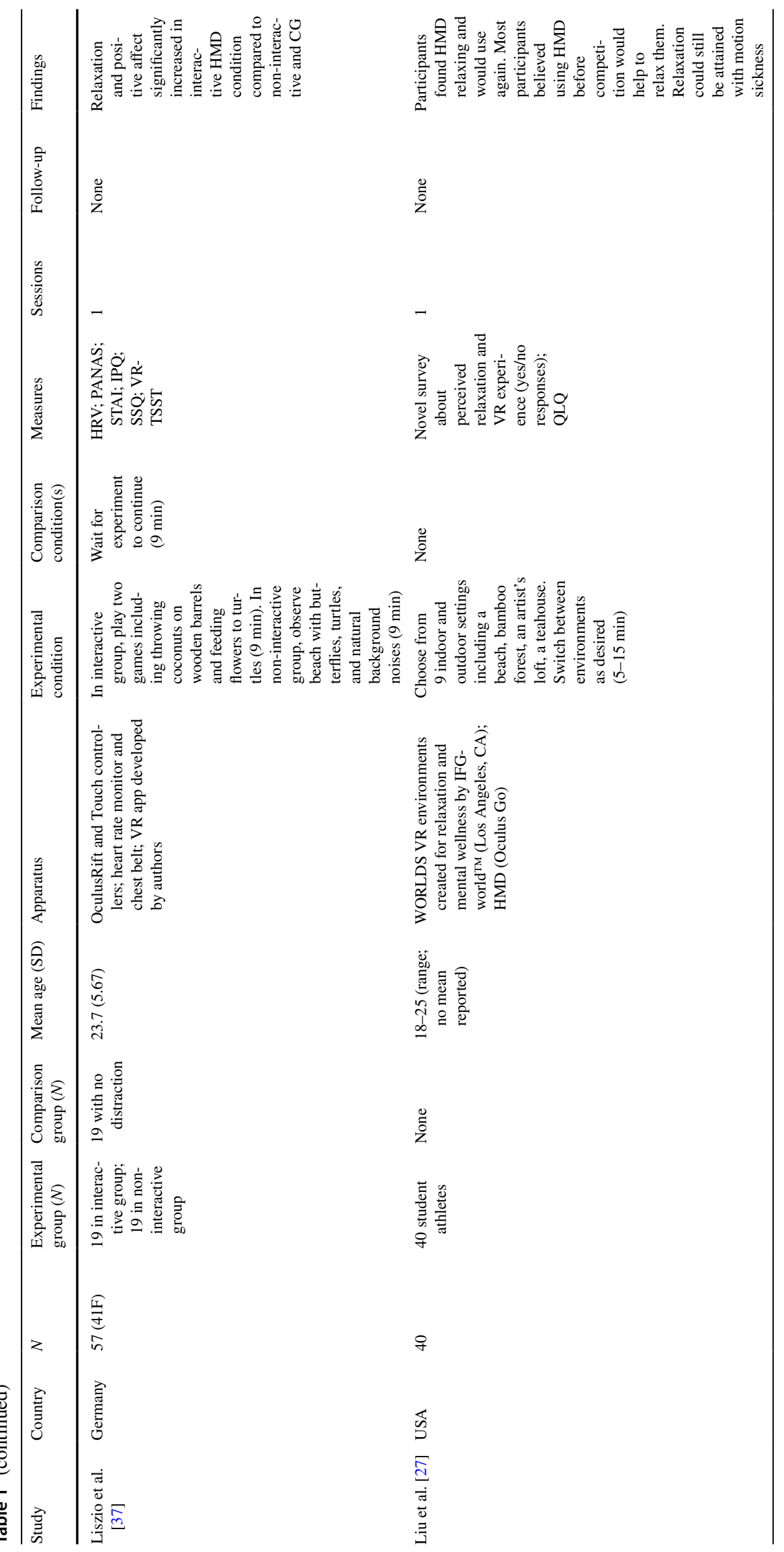




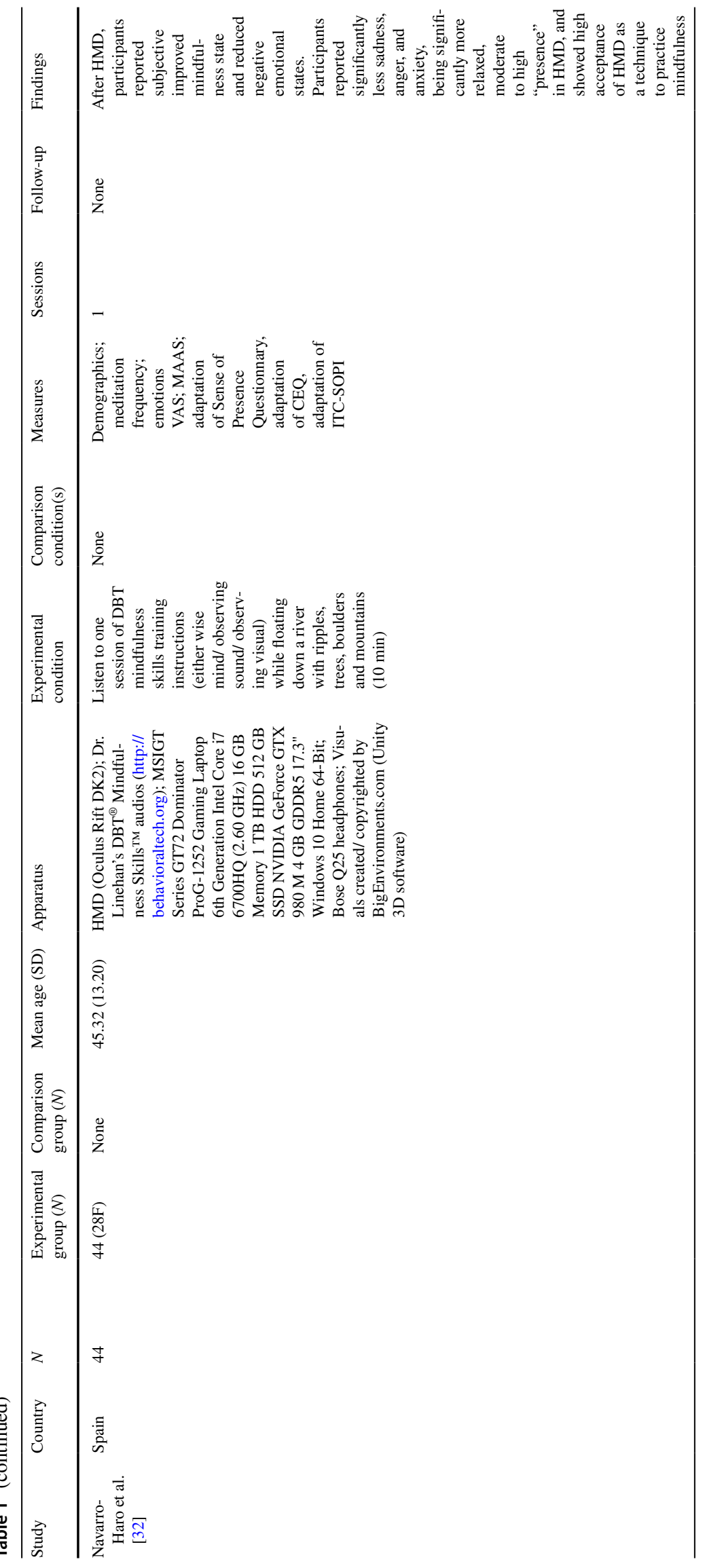




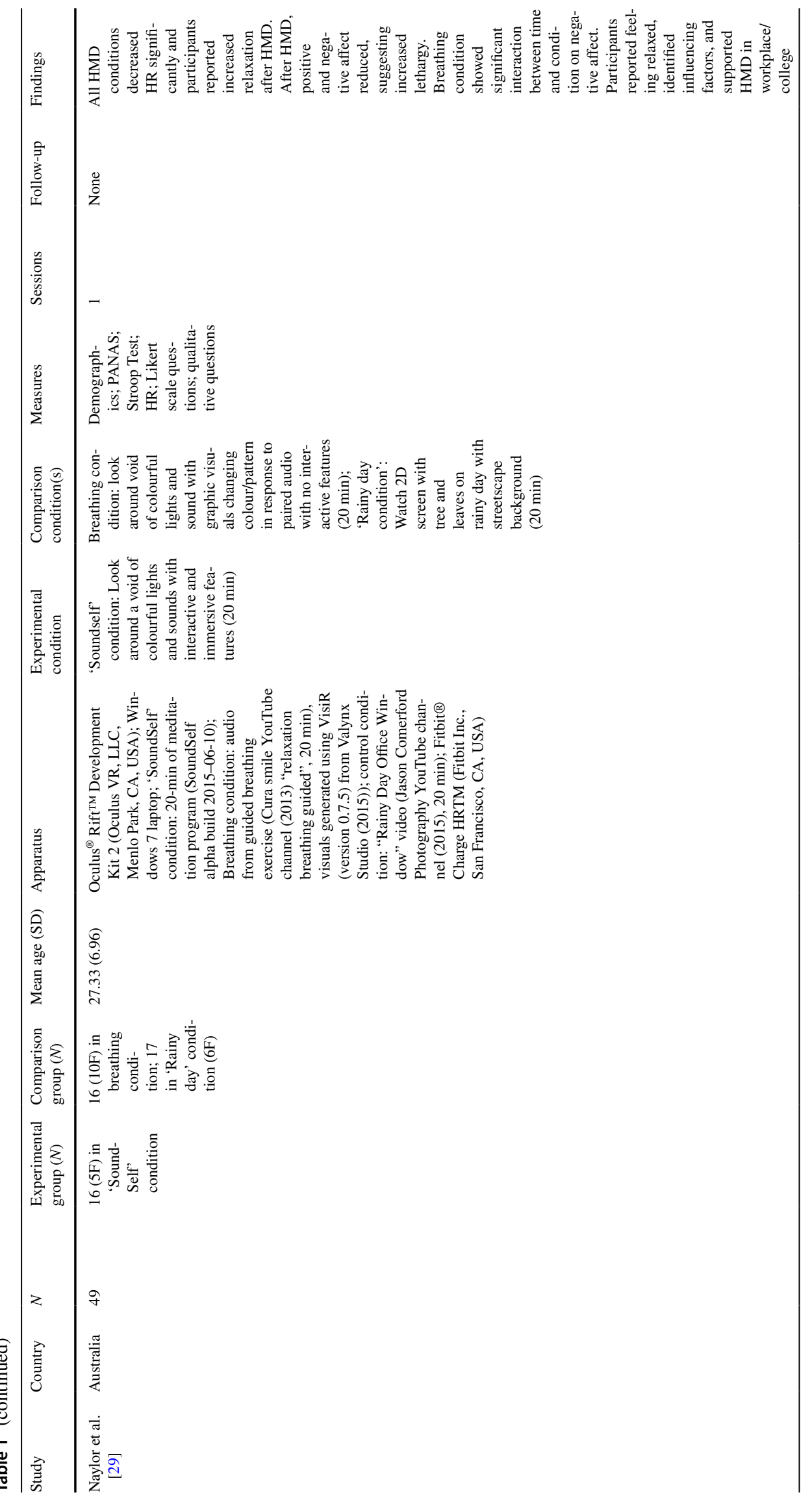




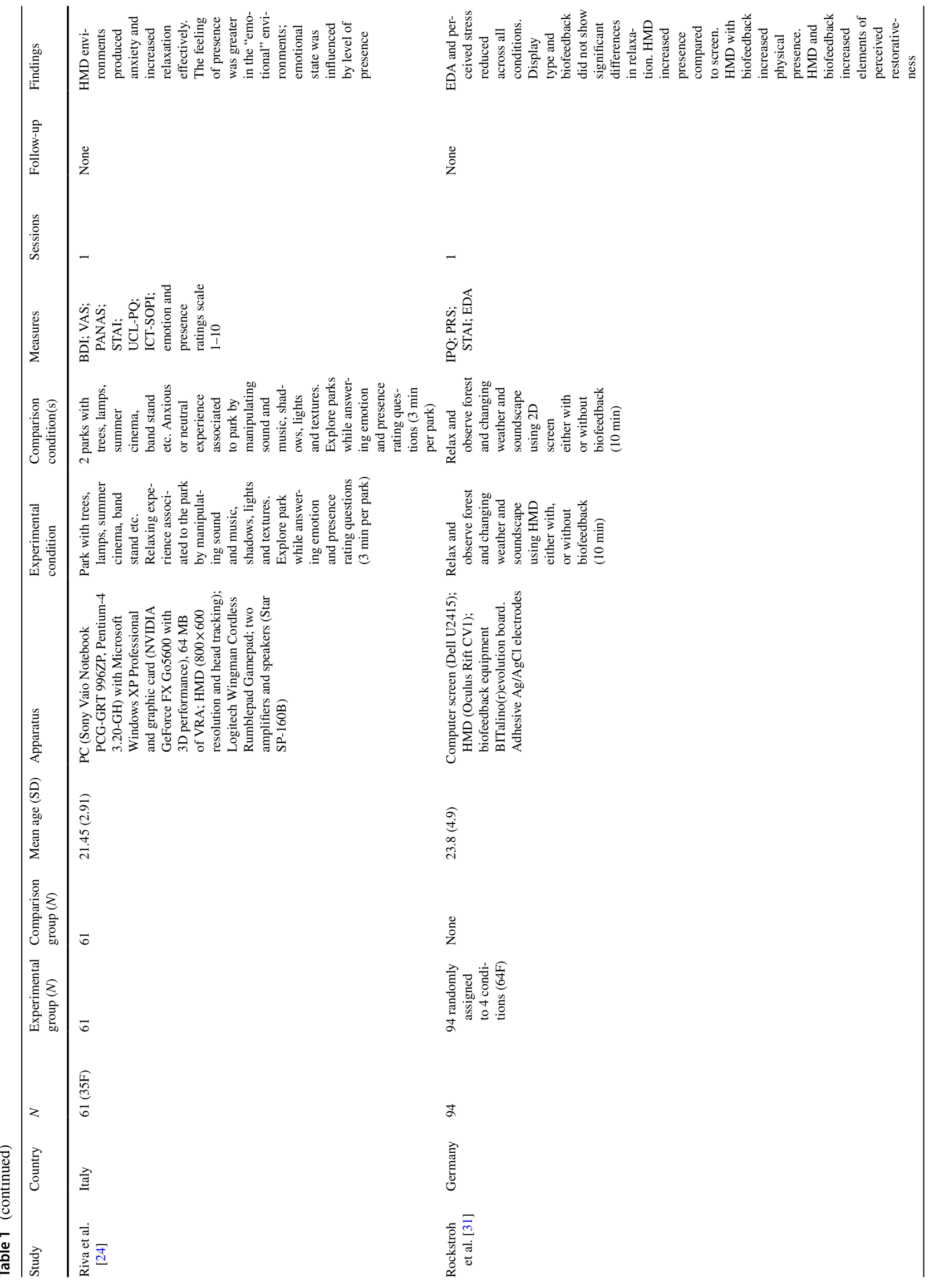




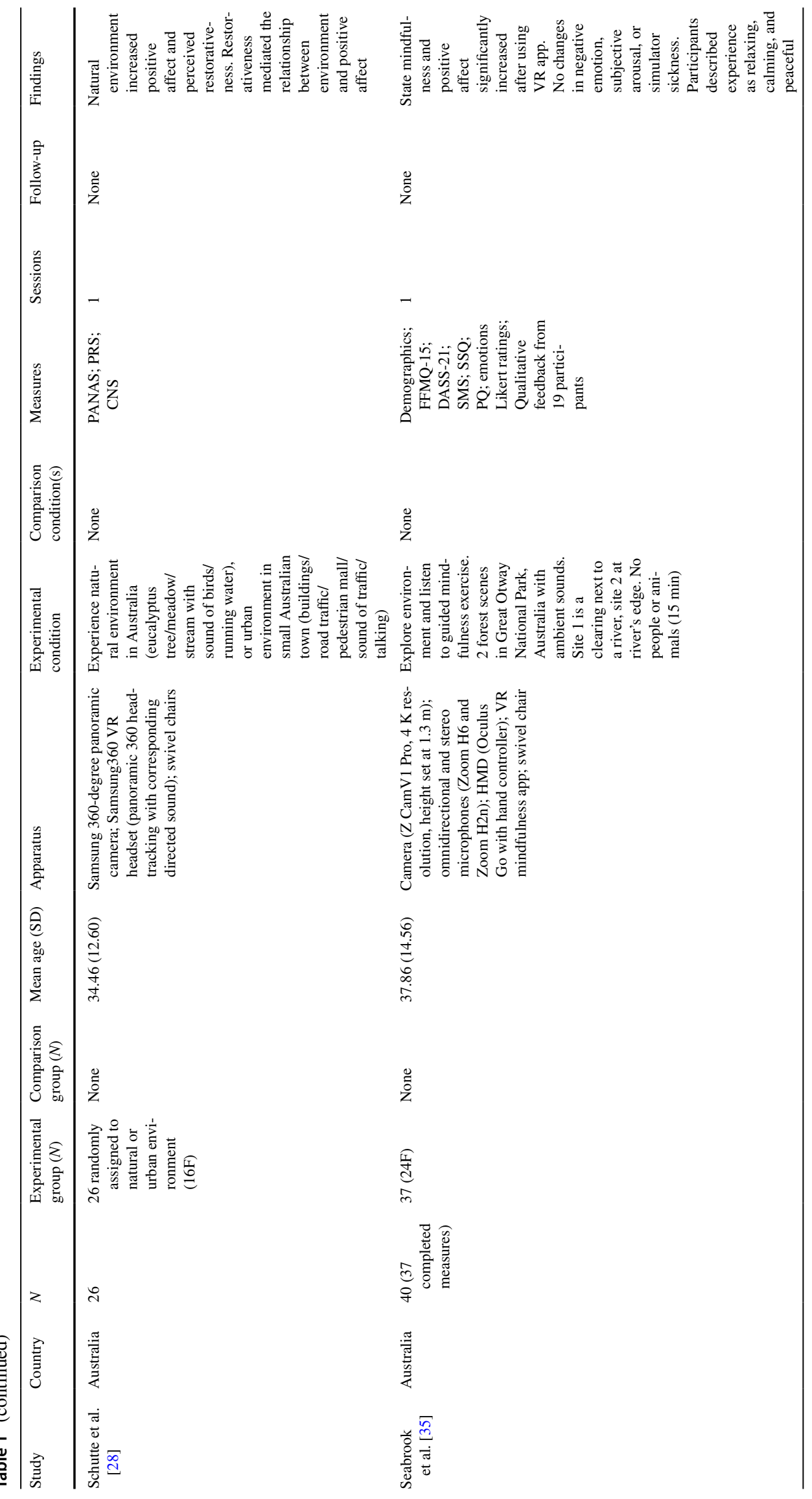




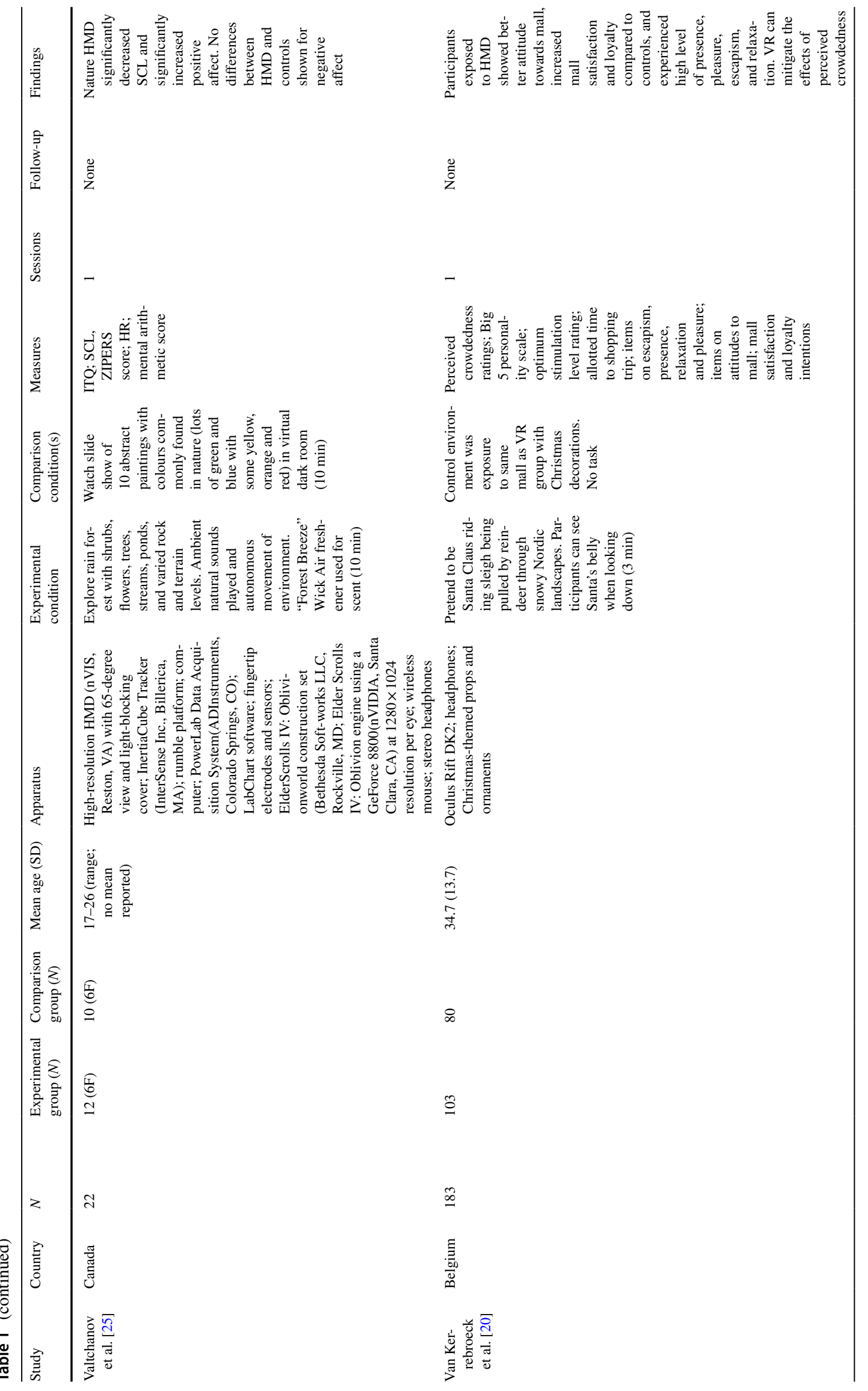




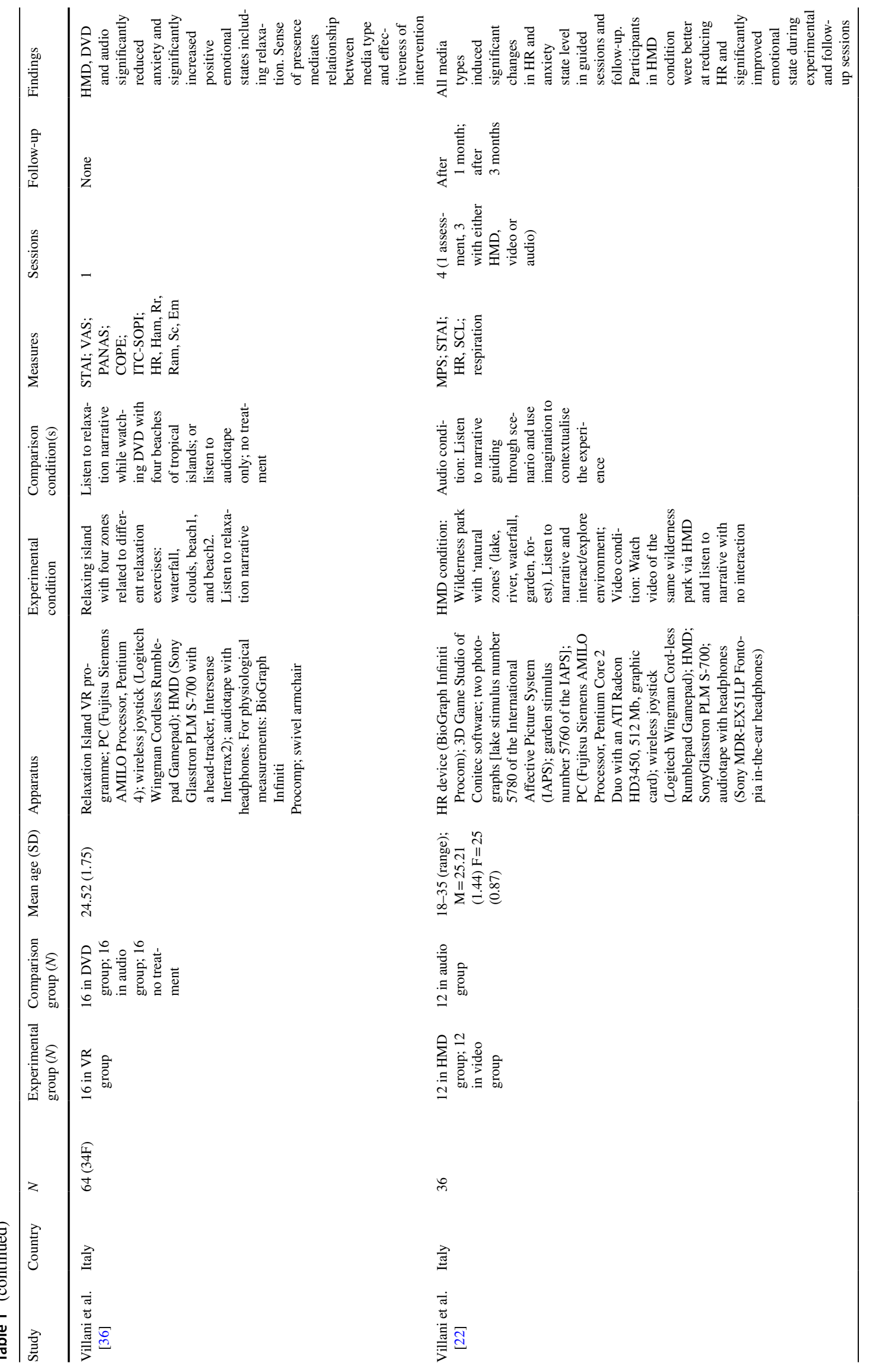




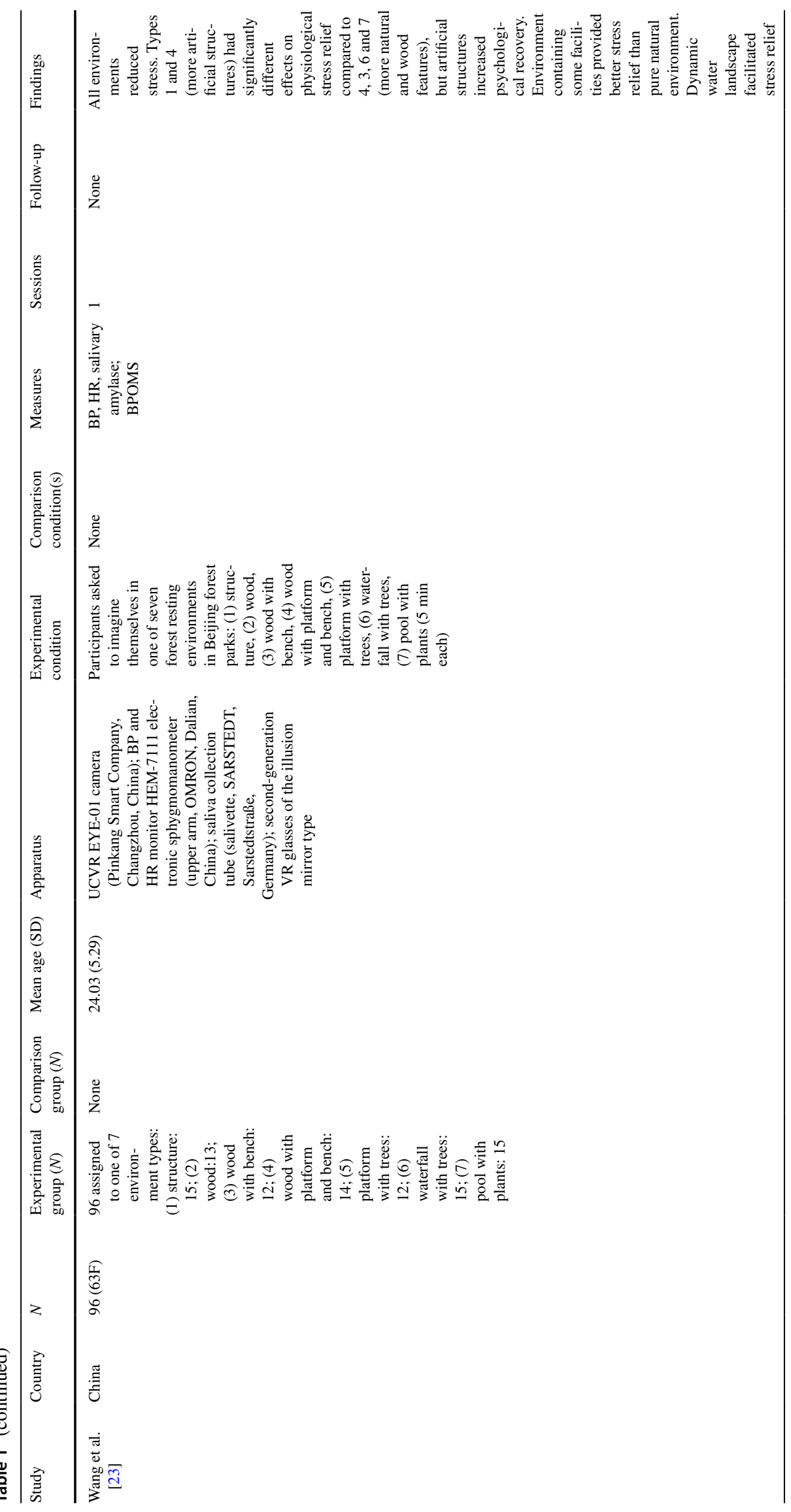




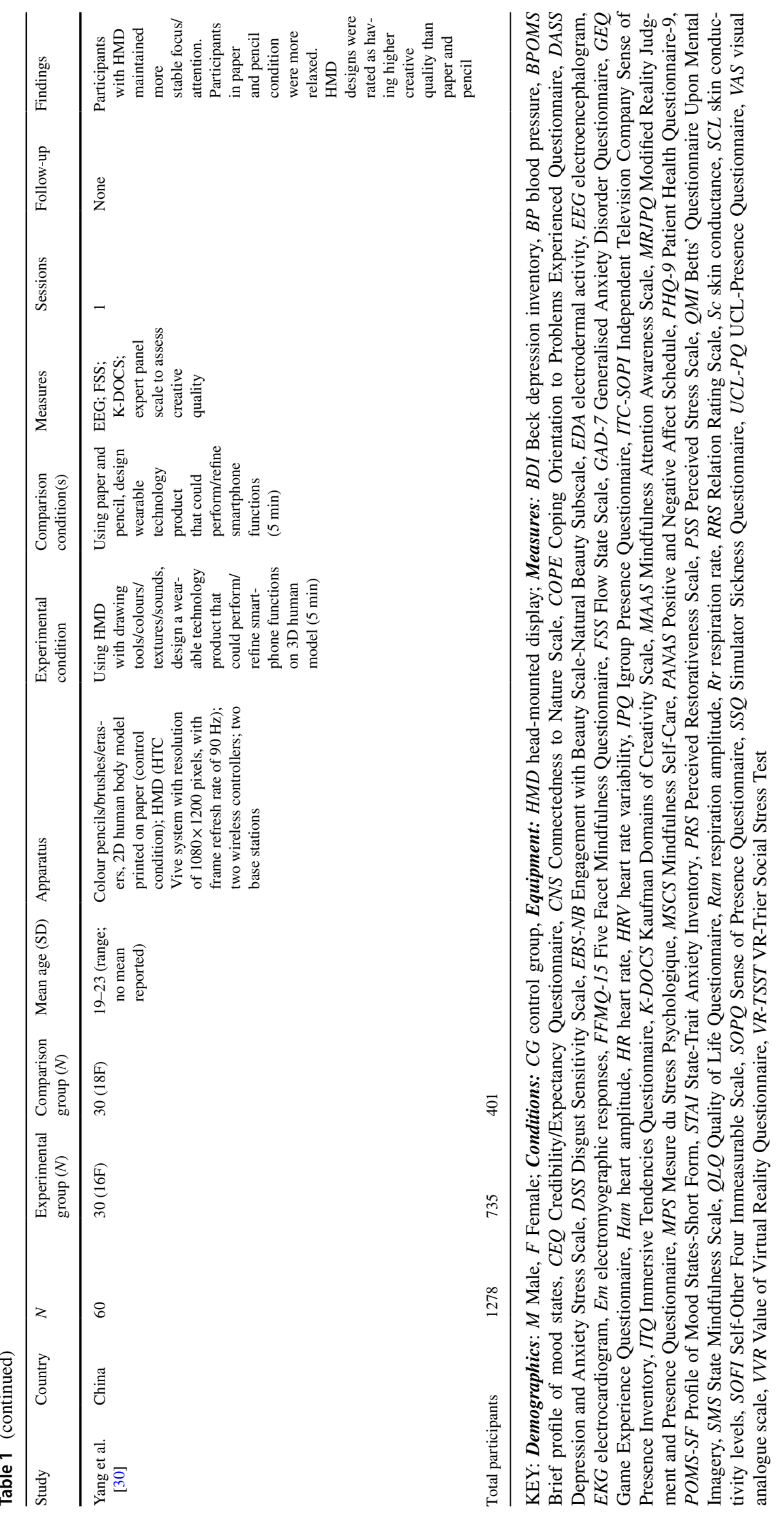


Table 2 Quality ratings of studies on virtual reality relaxation for the general population

\begin{tabular}{|c|c|c|c|c|c|c|c|}
\hline Study & A. Selection bias & B. Study design & C. Confounders & D. Blinding & $\begin{array}{l}\text { E. Data } \\
\text { collection } \\
\text { method }\end{array}$ & $\begin{array}{l}\text { F. Withdrawals } \\
\text { and drop out }\end{array}$ & Global rating \\
\hline $\begin{array}{l}\text { Anderson et } \\
\text { al. (2017) } \\
{[33]}\end{array}$ & MODERATE & MODERATE & WEAK & MODERATE & STRONG & STRONG & MODERATE \\
\hline $\begin{array}{l}\text { Browning et } \\
\text { al. (2020) } \\
{[26]}\end{array}$ & MODERATE & STRONG & STRONG & MODERATE & STRONG & STRONG & STRONG \\
\hline $\begin{array}{l}\text { Cebolla et } \\
\text { al. (2019) } \\
{[21]}\end{array}$ & MODERATE & STRONG & STRONG & MODERATE & STRONG & STRONG & STRONG \\
\hline $\begin{array}{l}\text { Gao et al. } \\
\text { (2019) [19] }\end{array}$ & MODERATE & STRONG & WEAK & MODERATE & WEAK & STRONG & WEAK \\
\hline $\begin{array}{l}\text { Liszio et al. } \\
\text { (2018) [34] }\end{array}$ & MODERATE & STRONG & WEAK & MODERATE & WEAK & STRONG & WEAK \\
\hline $\begin{array}{l}\text { Liszio et al. } \\
\text { (2019) [37] }\end{array}$ & STRONG & STRONG & STRONG & MODERATE & WEAK & STRONG & MODERATE \\
\hline $\begin{array}{l}\text { Liu et al. } \\
\text { (2019) [27] }\end{array}$ & MODERATE & WEAK & STRONG & MODERATE & WEAK & STRONG & WEAK \\
\hline $\begin{array}{l}\text { Navarro- } \\
\text { Haro et al. } \\
(2017) \text { [32] }\end{array}$ & MODERATE & MODERATE & STRONG & MODERATE & STRONG & STRONG & STRONG \\
\hline $\begin{array}{l}\text { Naylor et al. } \\
(2020) \text { [29] }\end{array}$ & STRONG & STRONG & WEAK & MODERATE & STRONG & STRONG & MODERATE \\
\hline $\begin{array}{l}\text { Riva et al. } \\
(2007)[24]\end{array}$ & MODERATE & MODERATE & WEAK & MODERATE & WEAK & STRONG & WEAK \\
\hline $\begin{array}{l}\text { Rockstroh } \\
\text { et al. }(2020) \\
{[31]}\end{array}$ & STRONG & STRONG & STRONG & MODERATE & WEAK & STRONG & MODERATE \\
\hline $\begin{array}{l}\text { Schutte et } \\
\text { al. (2017) } \\
{[28]}\end{array}$ & MODERATE & STRONG & STRONG & MODERATE & STRONG & STRONG & STRONG \\
\hline $\begin{array}{l}\text { Seabrook et } \\
\text { al. }(2020) \\
{[35]}\end{array}$ & STRONG & MODERATE & STRONG & MODERATE & STRONG & STRONG & STRONG \\
\hline $\begin{array}{l}\text { Valtchanov } \\
\text { et al. (2010) } \\
{[25]}\end{array}$ & MODERATE & STRONG & STRONG & MODERATE & STRONG & STRONG & STRONG \\
\hline $\begin{array}{l}\text { Van } \\
\text { Kerrebroeck } \\
\text { et al. (2017) } \\
{[20]}\end{array}$ & MODERATE & WEAK & STRONG & MODERATE & WEAK & STRONG & WEAK \\
\hline $\begin{array}{l}\text { Villani et al. } \\
\text { (2007) [36] }\end{array}$ & MODERATE & STRONG & WEAK & MODERATE & WEAK & STRONG & WEAK \\
\hline $\begin{array}{l}\text { Villani et al. } \\
\text { (2012) [22] }\end{array}$ & STRONG & STRONG & WEAK & MODERATE & STRONG & STRONG & MODERATE \\
\hline $\begin{array}{l}\text { Wang et al. } \\
\text { (2019) [23] }\end{array}$ & MODERATE & STRONG & WEAK & MODERATE & STRONG & STRONG & MODERATE \\
\hline $\begin{array}{l}\text { Yang et al. } \\
(2018)[30]\end{array}$ & MODERATE & STRONG & WEAK & MODERATE & STRONG & STRONG & MODERATE \\
\hline
\end{tabular}

\begin{tabular}{|l|}
\hline WEAK \\
\hline MODERATE \\
\hline STRONG \\
\hline
\end{tabular}

terrain elevations. The RCTs displayed forest or wilderness scenery with lakes, rivers, waterfalls, gardens [22], shrubs, trees, flowers, rocks, terrain elevations [25], vegetation, water, and wooden structures [23]. Six studies included both natural and urban elements in the virtual environments [19, 20, 24, 26-28]. Studies with larger sample sizes included virtual environments consisting of a combination of nature and urban-related stimuli such as sleighs, reindeers, snow [20], public spaces, and greenery [19]. Of these six studies, three compared natural virtual environments with urban virtual environments [19, 27, 28]. Two studies used guided meditation combined with audio-visual features [21, 29], and one applied a drawing activity on a three-dimensional human-like model [30].

Thirteen studies explicitly specified relaxation as a primary outcome variable, among other outcome variables. Measures, such as heart rate variability and skin conductivity levels, were employed to assess relaxation scores pre- and 
post-intervention. Six studies measured relaxation indirectly through relaxation-related variables such as restoration [19, 26, 28, 31] and stress [23, 25].

\section{Quality assessment}

Six studies received a global rating of 'strong', seven were 'moderate', and six were 'weak'. Of these, two studies lacked clarity and detail on study design, nine on confounding variables, and eight on data collection method. See Table 2 for quality ratings. Selection bias was moderate in fourteen studies given that participants were considered representative of the general population. Study designs of thirteen studies were strong because participants were randomly allocated to conditions. Of these, four were RCTs and nine were classified as controlled clinical trials because no method of randomisation was described. Controlling of confounding variables was rated as strong in ten studies. Blinding was moderate in all studies because they lacked information on whether outcome assessors were aware of the intervention or exposure status of participants and whether participants were aware of research questions. Data collection tools were strong in eleven studies. Withdrawals and drop-outs were strong in all studies due to completion rates between 80 and $100 \%$.

\section{Feasibility}

Nine of the nineteen studies explicitly evaluated feasibility. All indicated that VR is feasible to support and promote relaxation. Of these, five studies indicated that VR is costeffective and is becoming widely accessible to the general public [22, 25, 26, 29, 32]; however, this mainly consisted of commenting on the cost-effectiveness of VR rather than using primary data to support their claims. Two RCTs indicated that the general population can benefit from the availability and affordability of VR to help alleviate and manage stress $[22,25]$. One study with a large sample $(N=183)$ found that in stressful or chaotic situations, such as crowded shopping areas, VR can be a practical way to facilitate relaxation and enjoyment [20]. Two studies indicated that VR is a convenient and easy-to-use tool that supports wellbeing in the general population, particularly for those who have limited time [33] or cannot access the restorative benefits of nature [34]. Two studies reported minor limitations with regard to feasibility: in one study, a small number of participants reported physical difficulties with wearing the HMD [29] and another study reported that the weight of the HMD needs to be tolerable for VR relaxation to be feasible [35].

\section{Acceptability}

Six of the nineteen studies explicitly evaluated acceptability of VR relaxation. Of these studies, five supported the acceptability of HMD relaxation [27, 29, 32, 33, 35] and one study reported inconclusive results [34]. In general, participants found VR relaxation interventions positive, enjoyable, valuable [33], calming, and peaceful [35]. Studies reported that $80 \%$ of participants would recommend VR relaxation to manage stress [29] and $90 \%$ of participants wished to experience VR relaxation again [27]. VR relaxation was found to be a highly useful tool to support mindfulness practice [32]. Acceptability was less clear in one study that included a virtual simulation of an underwater environment [34]. Although experiencing the virtual underwater environment was enjoyable for most participants, a small number felt uncomfortable due to the "open water" or expressed concerns about sea creatures.

\section{Effectiveness}

Thirteen of the nineteen studies measured relaxation as a primary outcome. The main measurement tools used to assess relaxation were heart rate, self-report questionnaires such as the Positive and Negative Affect Schedule or the State-Trait Anxiety Inventory, or visual analogue scales on perceived relaxation. Ten studies reported increased relaxation in VR conditions, two found increased relaxation in HMD and comparison conditions of 2D graphic visuals [29] and DVD or audio [36], and one found increased relaxation in the comparison condition of a 2D drawing task only [30]. Two RCTs with follow-up data found that relaxation increased in HMD experimental conditions, compared to comparison conditions [21, 22]. Of these, one study showed that meditation combined with embodied VR increased the frequency of mindful relaxation compared to the comparison condition of meditation without embodied VR [21]. When compared to $2 \mathrm{D}$ video or audio, one study found that a wilderness virtual environment combined with relaxation exercises and a relaxing narrative in VR produced increases in relaxation [22]. In terms of follow-up data, these studies found that participants in HMD conditions experienced increases in the frequency of clinical self-care behaviours two weeks following the initial intervention [21] and were better at reducing their heart rate level and improving their emotional state one month and three months following the initial intervention [22]. One study with a large sample $(N=183)$ found that participants in a shopping centre exposed to a snowy, Christmas-themed virtual environment experienced increased relaxation [20]. In terms of relaxation-related variables, four studies reported increases in restoration $[19,26,28,31]$ and two reported decreases in stress $[23,25]$ in HMD conditions. One study with a large sample $(N=120)$ included virtual environments 
varying in urban space and vegetation and showed that these increased restoration in terms of improving directed attention and negative mood [19]. Another study reported greater increases in positive mood, as well as relaxation, in interactive HMD condition compared to non-interactive HMD and wait-list comparison conditions [37].

\section{Discussion}

\section{Summary of findings}

This systematic review aimed to synthesise current evidence on feasibility, acceptability, and effectiveness of VR relaxation in the general population. Nineteen studies were included in the review, of which four were RCTs. VR was shown to be a feasible and acceptable tool to promote relaxation. Virtual environments with pleasant, often natural, stimuli improved relaxation and relaxation-related variables, such as restoration and stress, when compared to comparison conditions.

These findings are consistent with research indicating that VR is more assessable and more affordable to members of the general public than it has ever been $[33,38]$, while it is important to recognise that this technology remains prohibitively expensive to many individuals and that social inequalities may contribute to a digital divide [22, 25, 39]. Although practical issues and safety concerns, such as the weight of the headset, were highlighted by a minority of participants $[29,35]$, recent developments in HMD have ensured that headsets are lightweight and comfortable [11]. High levels of acceptability found in this review are consistent with the view that HMD is a safe tool to support mental health and wellbeing [40].

In most studies included in this review, relaxation scores were significantly higher in HMD experimental conditions than in comparison conditions. This is consistent with previous research that indicates that pleasant and immersive virtual environments support and promote relaxation [41], stress restoration [42], and positive mood [43]. Many of the studies that reported increases in relaxation included audio and visuals of nature, which is consistent with existing research on the effectiveness of nature-related stimuli in facilitating stress recovery [12]. The combination of natural audio-visual features in virtual environments has been shown to activate the parasympathetic system and facilitate relaxation, stress recovery, and mood regulation [25, 44]. Therefore, experiencing natural virtual environments in VR is a promising alternative to obtaining the restorative effects of contact with real-world nature, especially for people who may be unable to access nature or outdoor environments.

\section{Strengths and limitations of studies included in the review}

Strengths of the studies included the prevalence of control or comparison conditions, which enabled researchers to isolate and attribute changes in outcome variables to VR relaxation, and the employment of both physiological and psychological measures. Limitations included the prevalence of young adult and student samples which means that findings may not generalise to other age groups or people of lower education, the relatively small sample sizes, the limited number of sessions, and the lack of follow-up data. Greater numbers of sessions and follow-ups are fundamental to ascertain if positive effects can be maintained. Without this longitudinal data, it is unclear whether there are any sustained or longerterm benefits. Studies were subject to various forms of bias. For instance, reliance on researcher-administered self-report measures may have led to more favourable reporting by participants, and the prevalence of the single-session format may have led to a novelty bias, in that positive evaluation might be attributable to the novelty of VR rather than the intervention itself. Overall, the methodological quality of the studies varied. While most studies stated that participants were randomly allocated to conditions, only four studies described the method of randomisation employed and were classified as RCTs.

\section{Strengths and limitations of the review}

This is the first review to focus on the feasibility, acceptability, and effectiveness of VR relaxation for the general population. The methodology included formal searches on electronic academic databases, as well as non-indexed searching of reference lists. The methods increased the number of studies identified and strengthened the confidence that conclusions arising from this review can be based on the synthesis of all relevant and available research. Screening, data extraction, and quality ratings were completed by two independent researchers, which ensured for an accurate and objective process.

A key limitation of this review is that heterogeneity of concepts limited comparisons between studies and reduced the reliability of findings that were synthesised. In particular, the operational definition of 'relaxation' in previous research is broad and comprises multiple facets. The current review identifies a lack of consistency and standardisation of definitions, measures, and interventions of relaxation across the studies reviewed. Although some studies stated relaxation as a primary outcome measure, definitions of relaxation were varied, with some inconsistencies, and there were no formal, validated measures of relaxation. Instead, studies employed physical parameters, idiosyncratic self-report measures, or psychometrics of relaxation-related variables. Single items 
on perceived relaxation were sometimes included in selfreport measures; however, there was no stand-alone measure of relaxation. Similarly, virtual environments intended to promote relaxation were diverse. While most studies used natural virtual environments, other studies combined both natural and urban features. As a result, caution is needed when comparing studies, and the conclusion that naturebased virtual environments are effective to promote relaxation should be stated tentatively.

\section{Applications to improve wellbeing}

The finding that VR relaxation improves relaxation and relaxation-related variables, such as stress, in the general population indicates that VR may be a useful tool to promote relaxation in the home and workplace. Existing studies have highlighted the benefits of VR relaxation and stress management in worker populations highly exposed to stress [45]. This, together with studies included in this review, indicates the potential value of VR to aid the public in managing and preventing cumulative stress. In line with a recent scoping review, studies reviewed indicate that HMD with natural virtual environments is a feasible and acceptable strategy that can be integrated into stressful and demanding situations, such as workplace settings, to improve relaxation and stress levels [46]. Previous studies have established the mental health benefits of VR relaxation in key workers, such as healthcare professionals, experiencing high levels of workrelated stress and burnout [47, 48]. Consistent with the studies included in this review, research has shown that workers feel more relaxed after experiencing VR relaxation and respond favourably to the implementation of VR relaxation interventions at work [49].

VR relaxation may have significant public health benefits during the COVID-19 pandemic. This is an unprecedented and hugely challenging situation that has elevated the rates of stress and fear in societies worldwide [50]. Emotional and socio-economic instabilities have been suggested to account for this [51, 52]. Due to government guidelines of social distancing, remote working, and self-isolation in lockdowns, a large proportion of the population are confined to their homes with limited social interaction, which may negatively impact on mental health, particularly in vulnerable groups [53], and the potential for virtual natural environments to support people who cannot experience real-world nature could be significant for both home use and the remote interventions facilitated by health services. For instance, VR relaxation could be trialled as a low-intensity intervention in mental health services. Systematic reviews have established VR as an effective treatment for a range of mental health problems, such as anxiety disorders and psychosis [10]. Extensive evidence suggests that the implementation of VR in clinical settings improves coping strategies [54], safety-seeking behaviours [54], sense of presence [55], and social cognition $[40,56,57]$ in mental health service users. VR relaxation could also benefit service users in psychiatric wards where they may be experiencing high levels of stress [58].

\section{Future research}

Future research should aim to standardise definitions, measures, and interventions; and consider demographic and social differences within participants. Larger-scale RCTs and longitudinal studies are critical to establishing the effectiveness of virtual environments and clarifying longer-term benefits. The duration of intervention exposure that is optimal in ensuring the feasibility and effectiveness of HMD relaxation remains inconclusive [20] and so should be tested in more robust studies. Future research might test the psychological benefits of natural virtual environments in VR relaxation, but with consideration to the variety of natural stimuli, given that underwater environments may elicit fears or anxieties [34].

\section{Conclusions}

This review is the first to narratively synthesise the literature on VR relaxation in the general population. Most studies combined nature-based virtual environments with soothing sounds or narratives of guided meditation or breathing, and all reported significant increases in relaxation or relaxation-related variables. However, methodological limitations restrict the wider generalisability of findings and any conclusions must be drawn with caution. Nevertheless, VR appears to be a promising tool to facilitate relaxation and stress management in people experiencing high levels of stress; it can be a practical and accessible intervention that enables people to relax at work or at home; and it may have particular relevance in the COVID-19 pandemic given that worldwide stress is on the rise.

Supplementary Information The online version contains supplementary material available at https://doi.org/10.1007/s00127-021-02110-z.

Author contributions All authors contributed to the study conception and design. The literature search and data analysis were performed by LA, SP, and SR. The first draft of the manuscript was written by SR and LA. All authors commented on previous versions of the manuscript. All authors read and approved the final manuscript.

Funding SR acknowledges financial support from the Health Innovation Network. LV acknowledges financial support from the National Institute for Health Research (NIHR) Biomedical Research Centre for Mental Health at South London and Maudsley NHS Foundation Trust and King's College London. 


\section{Declarations}

Conflict of interest The authors declare that they have no competing interest.

Open Access This article is licensed under a Creative Commons Attribution 4.0 International License, which permits use, sharing, adaptation, distribution and reproduction in any medium or format, as long as you give appropriate credit to the original author(s) and the source, provide a link to the Creative Commons licence, and indicate if changes were made. The images or other third party material in this article are included in the article's Creative Commons licence, unless indicated otherwise in a credit line to the material. If material is not included in the article's Creative Commons licence and your intended use is not permitted by statutory regulation or exceeds the permitted use, you will need to obtain permission directly from the copyright holder. To view a copy of this licence, visit http://creativecommons.org/licenses/by/4.0/.

\section{References}

1. Klainin-Yobas P, Oo WN, Suzanne Yew PY, Lau Y (2015) Effects of relaxation interventions on depression and anxiety among older adults: a systematic review. Aging Ment Heal 19(12):1043-1055

2. Li M, Wang L, Jiang M, Wu D, Tian T, Huang W (2020) Relaxation techniques for depressive disorders in adults: a systematic review and meta-analysis of randomised controlled trials. Int $\mathrm{J}$ Psychiatry Clin Pract 24(3):219-226

3. Balaji PA, Varne SR, Ali SS (2012) Physiological effects of yogic practices and transcendental meditation in health and disease. $\mathrm{N}$ Am J Med Sci 4(10):442-448

4. Nahar S, Gurav R (2018) Practice of relaxation techniques amongst working women. Practice 3(1):226-229

5. Seymour L (2010) Common mental health problems and work: applying evidence to inform practice. Perspect Public Health 130(2):59-60

6. Wiegner L, Hange D, Björkelund C, Ahlborg G (2015) Prevalence of perceived stress and associations to symptoms of exhaustion, depression and anxiety in a working age population seeking primary care-an observational study. BMC Fam Pract 16(1):1-8

7. Thoits PA (2010) Stress and health: major findings and policy implications. J Health Soc Behav 51(1_suppl):S41-53

8. Horesh D, Brown AD (2020) Covid-19 response: traumatic stress in the age of Covid-19: a call to close critical gaps and adapt to new realities. Psychol Trauma Theory Res Pract Policy 12(4):331-335

9. Brewin CR, DePierro J, Pirard P, Vazquez C, Williams R (2020) Why we need to integrate mental health into pandemic planning. Perspect Public Health 140:309-310

10. Valmaggia LR, Latif L, Kempton MJ, Rus-Calafell M (2016) Virtual reality in the psychological treatment for mental health problems: an systematic review of recent evidence. Psychiatry Res 236:189-195

11. Jerdan SW, Grindle M, Van Woerden HC, Kamel Boulos MN (2018) Head-mounted virtual reality and mental health: critical review of current research. J Med Internet Res 20(7):e14

12. Annerstedt $M$, Jönsson $P$, Wallergård M, Johansson G, Karlson B, Grahn P et al (2013) Inducing physiological stress recovery with sounds of nature in a virtual reality forest-results from a pilot study. Physiol Behav 118:240-250

13. Serrano B, Baños RM, Botella C (2016) Virtual reality and stimulation of touch and smell for inducing relaxation: a randomized controlled trial. Comput Hum Behav 55:1-8
14. Riva G, Baños RM, Botella C, Mantovani F, Gaggioli A (2016) Transforming experience: the potential of augmented reality and virtual reality for enhancing personal and clinical change. Front Psychiatry 7(SEP):164

15. Kim H, Kim EJ (2018) Effects of relaxation therapy on anxiety disorders: a systematic review and meta-analysis. Arch Psychiatr Nurs 32(2):278-284

16. Tabrizian P, Baran PK, Smith WR, Meentemeyer RK (2018) Exploring perceived restoration potential of urban green enclosure through immersive virtual environments. J Environ Psychol 55:99-109

17. Moher D, Liberati A, Tetzlaff J, Altman DG (2009) Preferred reporting items for systematic reviews and meta-analyses: the PRISMA statement. J Clin Epidemiol 62(10):1006-1012

18. National Collaborating Centre for Methods and Tools (2010) Quality assessment tool for quantitative studies. Eff Public Heal Pract Proj McMaster Univ Toronto 20(1998):1-4. http://www. ephpp.ca/index.html\%5Cn http://www.ephpp.ca/PDF/QualityAss essmentTool_2010_2.pdf

19. Gao T, Zhang T, Zhu L, Gao Y, Qiu L (2019) Exploring psychophysiological restoration and individual preference in the different environments based on virtual reality. Int J Environ Res Public Health 16(17):3102

20. Van Kerrebroeck H, Brengman M, Willems K (2017) Escaping the crowd: an experimental study on the impact of a virtual reality experience in a shopping mall. Comput Hum Behav 77:437-450

21. Cebolla A, Herrero R, Ventura S, Miragall M, Bellosta-Batalla M, Llorens R et al (2019) Putting oneself in the body of others: a pilot study on the efficacy of an embodied virtual reality system to generate self-compassion. Front Psychol 10:1521

22. Villani D, Riva G (2012) Does interactive media enhance the management of stress? Suggestions from a controlled study. Cyberpsychol Behav Soc Netw 15(1):24-30

23. Wang X, Shi Y, Zhang B, Chiang Y (2019) The influence of forest resting environments on stress using virtual reality. Int J Environ Res Public Health 16(18):3263

24. Riva G, Mantovani F, Capideville CS, Preziosa A, Morganti F, Villani D et al (2007) Affective interactions using virtual reality: the link between presence and emotions. Cyberpsychol Behav 10(1):45-56

25. Valtchanov D, Barton KR, Ellard C (2010) Restorative effects of virtual nature settings. Cyberpsychol Behav Soc Netw 13(5):503-512

26. Browning MHEM, Mimnaugh KJ, van Riper CJ, Laurent HK, LaValle SM (2020) Can simulated nature support mental health? Comparing short, single-doses of 360-degree nature videos in virtual reality with the outdoors. Front Psychol 10:2667

27. Liu M, Matsumura D (2019) A virtual reality relaxation intervention on NCAA division-one student athletes. EC Psychol Psychiatry 8(7):586-593

28. Schutte NS, Bhullar N, Stilinović EJ, Richardson K (2017) The impact of virtual environments on restorativeness and affect. Ecopsychology 9(1):1-7

29. Naylor M, Morrison B, Ridout B, Campbell A (2020) Augmented experiences: investigating the feasibility of virtual reality as part of a workplace wellbeing intervention. Interact Comput 31(5):507-523

30. Yang X, Lin L, Cheng PY, Yang X, Ren Y, Huang YM (2018) Examining creativity through a virtual reality support system. Educ Technol Res Dev 66(5):1231-1254

31. Rockstroh C, Blum J, Göritz AS (2020) Combining VR and biofeedback: the effects on perceived restorativeness and presence. $\mathrm{J}$ Media Psychol 32(4):176-186

32. Navarro-Haro MV, López-del-Hoyo Y, Campos D, Linehan MM, Hoffman HG, García-Palacios A et al (2017) Meditation experts try virtual reality mindfulness: a pilot study evaluation of the 
feasibility and acceptability of virtual reality to facilitate mindfulness practice in people attending a mindfulness conference. PLoS ONE 12(11):e0187777

33. Anderson AP, Mayer MD, Fellows AM, Cowan DR, Hegel MT, Buckey JC (2017) Relaxation with immersive natural scenes presented using virtual reality. Aerosp Med Hum Perform 88(6):520-526

34. Liszio S, Graf L, Masuch M (2018) The relaxing effect of virtual nature: immersive technology provides relief in acute stress situations. Annu Rev Cyberther Telemed 2018(16):87-93

35. Seabrook E, Kelly R, Foley F, Theiler S, Thomas N, Wadley $\mathrm{G}$ et al (2020) Understanding how virtual reality can support mindfulness practice: mixed methods study. J Med Internet Res 22(3):e16106

36. Villani D, Riva F, Riva G (2007) New technologies for relaxation: the role of presence. Int J Stress Manag 14(3):260-274

37. Liszio S, Masuch M (2019) Interactive immersive virtual environments cause relaxation and enhance resistance to acute stress. Annu Rev Cyberther Telemed 17:65-71

38. Mishkind MC, Norr AM, Katz AC, Reger GM (2017) Review of virtual reality treatment in psychiatry: evidence versus current diffusion and use. Curr Psychiatry Rep 19(11):80

39. Ramsetty A, Adams C (2020) Impact of the digital divide in the age of COVID-19. J Am Med Inform Assoc 27(7):1147-1148

40. Rus-Calafell M, Garety P, Sason E, Craig TJK, Valmaggia LR (2018) Virtual reality in the assessment and treatment of psychosis: a systematic review of its utility, acceptability and effectiveness. Psychol Med 48(3):362-391

41. Shah LBI, Klainin-Yobas P, Torres S, Kannusamy P (2014) Efficacy of psychoeducation and relaxation interventions on stressrelated variables in people with mental disorders: a literature review. Arch Psychiatr Nurs 28(2):94-101

42. Tyrväinen L, Ojala A, Korpela K, Lanki T, Tsunetsugu Y, Kagawa $\mathrm{T}$ (2014) The influence of urban green environments on stress relief measures: a field experiment. J Environ Psychol 38:1-9

43. Pritchard A, Richardson M, Sheffield D, McEwan K (2020) The relationship between nature connectedness and eudaimonic wellbeing: a meta-analysis. J Happiness Stud 21(3):1145-1167

44. Richardson M, McEwan K, Maratos F, Sheffield D (2016) Joy and calm: how an evolutionary functional model of affect regulation informs positive emotions in nature. Evol Psychol Sci 2(4):308-320

45. Gaggioli A, Pallavicini F, Morganti L, Serino S, Scaratti C, Briguglio $M$ et al (2014) Experiential virtual scenarios with realtime monitoring (interreality) for the management of psychological stress: a block randomized controlled trial. J Med Internet Res 16(7):e167

46. Naylor M, Ridout B, Campbell A (2020) A scoping review identifying the need for quality research on the use of virtual reality in workplace settings for stress management. Cyberpsychol Behav Soc Netw 23(8):506-518

47. Stetz MC, Kaloi-Chen JY, Turner DD, Bouchard S, Riva G, Wiederhold BK (2011) The effectiveness of technology-enhanced relaxation techniques for military medical warriors. Mil Med 176(9):1065-1070

48. Morse G, Salyers MP, Rollins AL, Monroe-DeVita M, Pfahler C (2012) Burnout in mental health services: a review of the problem and its remediation. Adm Policy Ment Heal Ment Heal Serv Res 39(5):341-352

49. Pretsch J, Pretsch E, Saretzki J, Kraus H, Grossmann G (2020) Improving employee well-being by means of virtual reality-REALEX: an empirical case study. Eur J Econ Bus Stud 6(1):95-105

50. Ozamiz-Etxebarria N, Dosil-Santamaria M, Picaza-Gorrochategui M, Idoiaga-Mondragon N (2020) Stress, anxiety, and depression levels in the initial stage of the COVID-19 outbreak in a population sample in the northern Spain. Cad Saude Publ 36(4):e00054020

51. Rajkumar RP (2020) COVID-19 and mental health: a review of the existing literature. Asian J Psychiatr 52:102066

52. Nicola M, Alsafi Z, Sohrabi C, Kerwan A, Al-Jabir A, Iosifidis C et al (2020) The socio-economic implications of the coronavirus pandemic (COVID-19): a review. Int J Surg 78:185-193

53. Holmes EA, O'Connor RC, Perry VH, Tracey I, Wessely S, Arseneault L et al (2020) Multidisciplinary research priorities for the COVID-19 pandemic: a call for action for mental health science. Lancet Psychiatry 7(6):547-560

54. Valmaggia L (2017) The use of virtual reality in psychosis research and treatment. World Psychiatry 16(3):246-247

55. Grochowska A, Jarema M, Wichniak A (2019) Virtual realitya valuable tool to advance treatment of mental disorders. Arch Psychiatry Psychother 21(12):65-73

56. Rus-Calafell M, Gutiérrez-Maldonado J, Ribas-Sabaté J (2014) A virtual reality-integrated program for improving social skills in patients with schizophrenia: a pilot study. J Behav Ther Exp Psychiatry 45(1):81-89

57. Ose SO, Færevik H, Kaasbøll J, Lindgren M, Thaulow K, Antonsen $\mathrm{S}$ et al (2019) Exploring the potential for use of virtual reality technology in the treatment of severe mental illness among adults in mid-Norway: collaborative research between clinicians and researchers. J Med Internet Res 21(6):e13633

58. Veling W, Sjollema MJ, Brada BC (2018) Reducing impact of stress in patients with psychiatric disorders: a pilot study on the effects of swimming with wild, free dolphins in virtual reality. Int J Child Heal Hum Dev 11(2):183-7. http://viemr.com 